\title{
IMMEDIATE MEMORY AND ITS EVALUATION.
}

\author{
By STANLEY H. WATKINS. \\ (University College of South Wales and Monmouthshire, Cardiff.) \\ I. Introduction. \\ II. Previous work on the evaluation of immediate memory. \\ III. The span of prehension. \\ IV. Errors of partial reproduction. \\ V. Impression and expression. \\ VI. Conclusions.
}

\section{INTRODUCTION.}

IN 1910-11 a series of experiments, among children of both sexes, was carried out by the writer in one of the Bezirkschulen at Leipzig $^{1}$, on the relation of intelligence to learning and remembering. Whilst broadly demonstrating that immediate memory is better in intelligent than in unintelligent children, these experiments at the same time indicated that this form of memory is of a much more complex nature than has been hitherto supposed. With a view to the further investigation of the nature of immediate memory and its different manifestations in varying degrees of intelligence, a fresh series of experiments was undertaken in the February and March of 1912 upon children from a South Wales school ${ }^{2}$. Experiments were also carried out upon four adults (two men and two women), all elementary school teachers, who had had no previous experience of experimental work, and, therefore, might be expected to be confronted with the same primary difficulties of learning as the children.

1 See "Beziehungen zwischen der Intelligenz und dem Lernen und Behalten," Päd.Psychol. Arbeiten, Ir. 65.

2 I am indebted to the Head-teachers and Staffs of the Dowlais Elementary Schools, who not only readily gave me permission to conduct my experiments, but also afforded me much valuable help in carrying them out. 
The children were 20 in number, ten boys and ten girls, and were taken from classes of 50 boys and girls respectively, whose average age amounted to ten years. The boys and girls had been divided by the class teachers into two groups, one containing intelligent, and the other backward children, the standard of general school work being taken as the basis of classification. The children were chosen in equal numbers from these two groups, but care was taken not to choose the very best children, so as to avoid, if possible, the precociously developed child; whilst those selected at the opposite extreme were, as far as was known, free from physical or mental defect.

In the case of the boys, the work was carried out in the afternoon, in a private room at the school, and with no one present except the experimenter and the subject. The girls were tested in the same fashion in the morning. The work with the adults was done under similar conditions, that with the men in the evening, with the women in the morning. The material adopted for use in the experiments consisted of numerals (single digits) and senseless syllables.

The numerals were arranged in one group of five series, each series consisting of nine rows containing respectively from two to ten units. The syllables were similarly arranged in two groups of five series, each series consisting of seven rows containing respectively from two to eight units ${ }^{1}$. The numbers were written, and the syllables typed, in vertical columns on unruled sheets of foolscap paper. This paper was enclosed in a folding sheet of thin blue cardboard, in which nine slots of varying length were cut, each slot being adapted to the length of a row. A similar sheet of cardboard containing a slot cut to fit the width of the row, and narrow enough to admit of the exposure of just one syllable or number at a time, was used by the subject. This was placed over the slot exposing the row of two units. The subject was then required to slide the sheet regularly down the row, repeating each unit aloud as it was exposed ${ }^{2}$. As soon as the last unit was read, the row was immediately repeated 'by heart,' in the same order, beginning, as far as was possible, with the first. No instructions, for obvious reasons, were given to avoid sensible associations, though, when they occurred, the subject was told not to rely on such associations as a means of reproduction. Sufficient time was given-varying with the

1 In the series arranged for the advlts, from two to ten units

2 It was thought advisable to let the child, rather than the experimenter, move the sheet. By this 'motor adjustment' the child was guarded from that state of mere passive expectancy which works so unfavourably when mechanical apparatus is used. 
rapidity in answering-to allow of efforts of recall. The sheet was then placed in position above the second row and the same procedure followed. The subject was informed of the length and nature of each row before it was exposed.

Some difficulty was experienced in choosing the mode of presenting the ruws. Previous work on the subject does not point to any very definite conclusions as to the most sutisfactory form of exposure. The weight of opinion seems to be in favour of the visual exposure of the rows, particularly of syllables. Binet ${ }^{1}$ inclined to the view that "l'expérience a appris qu'une multiplicité de sensations favorise la mémoire." Watt ${ }^{2}$ on the other hand writes that "there is not the slightest use in multiplying forms of imagery in the process of learning." As my main purpose was to investigate differences in the learning process, it was thought advisable to let the subjects learn the rows under conditions as similar as possible to those under which their usual school work was performed. They were, therefore, permitted both to see the material and to read it aloud. The rate of reading was left to the individual, care being taken, of course, that the rate was not so slow as to allow of any revisionul repetition of individual members before the whole row had been exposed. It was found that the children quickly adapted themselves to a rate of reading which tended to remain fairly constant, though it naturally varied considerably with different individuals. One exception had, however, to be made. The reading of the syllables was found to present considerable, if not an insuperable, difficulty to the more backward children. These rows were therefore read aloud by the experimenter, as well as by these children. This procedure, naturally, had obvious dungers. It was, however, decided on for the following reasons. In the first place, one child persisted in reading the syllables given in the preliminary test in a wrong form, though on reproducing them she apparentlyin the 'rows of two units at least-relied mainly upon her acoustic imagery, and gave the syllables correctly. Again, rows and even single syllables previously exposed had, especially with backward children, considerable influence upon a freshly exposed row. In consequence,

1 Les idées modernes sur les enfants, 122.

2 The Economy and Training of Memory, 101. Pohlmann (Exper. Beiträge zur Lehre vom Gedächtnis, 184-5) found, as one might expect, that syllables were better learnt visually and words orally. Opinions, however, differ on this point; see Hawkins, "Experiments on Mental Types," Psychol. Rev. 1897 and Meumann, Ökonomie und Technik des Gedächtnisses, 129. 
the row, either in whole or in part, was often not really apperceived, but rather assimilated to the persistent image. Such is the influence of this persistence that though the word was read properly to the child, yet some combination of it with the persistent image (e.g., see below, pp. 343 and 344) would often be read, and though the error was at once corrected by the child, it would afterwards be reproduced in combinations showing little variation.

As will have been gathered, the rows were reproduced orally. This plan was adopted in preference to the method of writing them down. In rows near the threshold of immediate memory especially, it is essential that they should be repeated immediately; otherwise the rapidly fading impressions are not capable of repetition. In such cases their reproduction in writing presents serious difficulties, for the act of writing inhibits the power of repetition, driving away the ever weakening impressions.

At the first sitting, when the numbers were given, a preliminary test of merely reading a row of numbers, and then of reading and reproducing rows of from two to five numbers was taken. This test was intended to give practice in the use of the cardboard sheet. Similarly, at the second sitting, a row of ten syllables was read through, and a series of three rows of from two to four units was read and reproduced. In the succeeding sittings, as each series began with a row of two units, no preliminary test was given, the repetition of this short row being regarded as sufficient preliminary exercise. The whole of the experiments comprised three sittings, one for the numbers, and one for each group of syllables.

\section{Previous work on the evaluation of immediate MEMORY.}

Before we proceed to a description of the results of our experiments, some review of previous work on immediate memory is necessary. It is now generally accepted that the intelligent child gives evidence of a better immediate memory than the backward, and a much better general memory than the weak-minded child. The methuds upon which such conclusions are based have not, however, been as yet subjected to any standardised evaluation. Most probably, this has been due to the emphasis laid on the value of the test as one of a series ${ }^{\mathbf{1}}$, where each test is intended mainly to produce a certain general estimate.

1 As in the Binet tests. 
The usual method adopted is,'Itherefore, to combine the results of any test of immediate memory. The numerical expression of these results is then regarded as evidence of intellectual grading. It is obvious that investigations of this nature depend upon quantitative rather than upon qualitative values. Thus, little stress has been laid on the functional differences which, especially in the case of immediate memory, play so important a rôle-differences, moreover, which may often modify to no small extent the value of the numerical results thus obtained. A glance at the history of the methods employed in the estimation of immediate memory will bring this out more clearly.

The method first adopted was that in which the given reproductions were taken en masse and estimated as a percentage of the total number of members in the whole of the rows presented. Jacobs ${ }^{1}$, in his experiments with syllables, numbers and letters on the span of prehension among adults and school children, took apparently only those rows which were given correctly, making no allowance for rows beyond the threshold, where misplacement either of digit, or of vowel, or consonant sound may have taken place. In this manner, a somewhat vague comparative estimate was obtained of the variations in immediate memory among children of varying grades. But it is clear that such a method, when adopted as a general estimate, is open to grave objection. Important matters, such as the order in which the units of the row are reproduced, to say nothing of individual differences in the mode of reproduction, are entirely passed over. Moreover, the many cases where the syllables are but partially reproduced (cases which provide material for the study of the most interesting of the differences that occur) are neglected, and are not given even partial values in the final estimate.

The next plan-one borrowed from methods employed in the investigation of mediate memory - was to take into account the manner in which the rows were reproduced. Thus the reproduction of a row of six syllables in their right order has a value quite different from that of a similar row the whole six units of which are repeated in the wrong order. To avoid such difficulties, a graded system of marking was adopted, and for this purpose two methods were devised ${ }^{2}$. In the first, or negative, method, marks were deducted for any failures committed. A numeral or letter omitted, for example, or one inserted which had no place in the row, caused the loss of one mark, whilst

1 “Experiments on Prehension," Mind, 1887, xIr. 75.

2 Cf. Smith, "Relation of Attention to Memory," Mind, 1895, Iv. 51. 
errors of misplacement were recognised by the loss of half a mark. In the second, or positive, method, marks were awarded in the following manner:- (a) for each unit named in the wrong position, or when the position was not known, one mark was given, (b) for each unit reproduced with imperfect knowledge of its position, two marks were given, whilst, $(c)$ if the units were reproduced correctly, it was given three marks'.

Here, then, each unit of the row is given a fairly definite place value, based on the assumption that to reproduce a row in the right order implies a better 'memory' of the row than is the case when it is reproduced in the wrong order. Such an assumption is at best but an arbitrary assignment of values, and is based apparently on the doubtful supposition that each individual member of a given row has an equal reproductive place value, irrespective of its position in the row. A glance, however, at the curves which plot the relative rate of forgetting 2 of the units in any given series of rows, shows the inherent weakness of this assumption. For, as is to be expected, the first and last units of the row are best remembered, and therefore have, one may assume, less value in point of reproductive difficulty, than those units situated nearer the middle of the row, which are more easily forgotten and therefore reproduced with more difficulty. Not only is this so, but in the case of rows near the threshold, where, in the attempt to preserve the unity of the row, the latter is sometimes repeated backwards, this method of valuation gives quite a wrong impression of the reproductive value of the first unit of the row, which would then be reproduced last in order. Most frequently its position is well known, its order in the row reproduced being due to the initial difficulty found in transferring the attention from the last given units, which tends to persevere to the detriment of those already presented ${ }^{3}$. This weakness has been recognised, and an attempt made to rectify it, in a method

1 Burt ("Experimental Tests of General Intelligence," This Journal, 1909), following Meumann (Ztsch. f. exp. Päd. ז. 69) who, however, himself uses the negative method, adopts the following values:-For every unit correctly given and correctly placed, four marks ; if one place out, three marks ; if more than one, two marks. For a unit correctly placed, but with either the initial or final consonant or medial vowel wrong, three marks; if incorrectly placed, two marks. For those units rightly placed but with two components altered, two marks were given.

2 Cf. Binet, "La mémoire des mots," L'Ann. psychol. 1894, 12 ; Bolton, "Growth of Memory in School Children," Amer. J. of Psychol. Iv. 379.

See note, p. 337. 
put forward by Wagner ${ }^{1}$, the primary object of which is to obtain some definite relationship, based on the place values, between the units of the row, as given, and as reproduced. The following diagram ${ }^{2}$ gives the most favourable case. Here, a series of eight rows containing from two to nine units is reproduced in the correct order:-

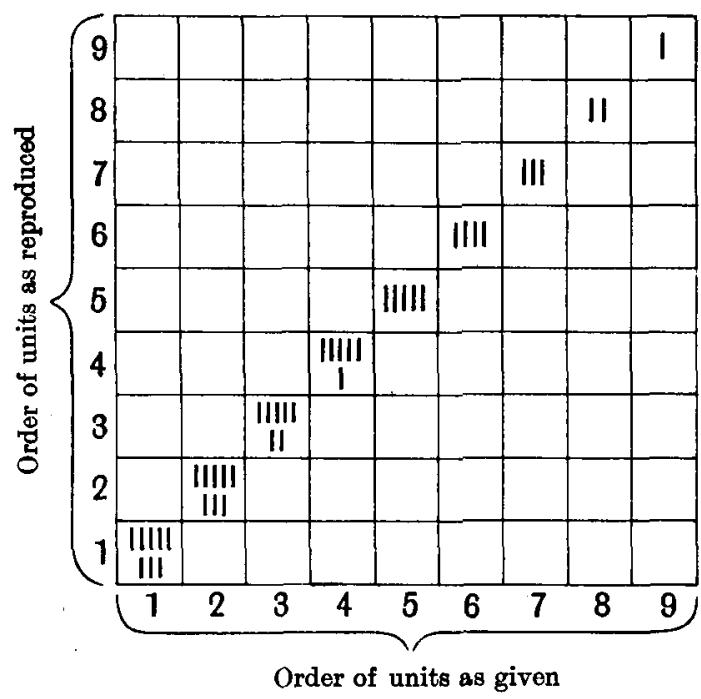

The units, if all correctly reproduced, would lie as above in one diagonal - the 'chief diagonal' - of the diagram. Assuming, now, that the worst case is that in which all the units of the row are reproduced, but in their inverse order, then the diagram would be represented as on page. 326 .

In such a case as this, where eight rows successively ranging from two to nine units are reproduced in inverse order, there will always be four units in the chief diagonal. This number must moreover vary with the number of the rows. Hence, if $m$ be taken as representing the number of units in the chief diagonal, when the rows are reproduced in inverse order (i.e., in the worst case), and $n$ the number of units in the longest row of the series presented, the following are the equations for uneven $\left(m_{1}\right)$ and even $\left(m_{2}\right)$ values of $m:-$

$$
m_{1}=\frac{n-1}{2}, \quad m_{2}=\frac{n-2}{2} .
$$

1 "Die rechnerische Behandlung d. Ergebnisse bei der Prüfung des unmittl. Behaltens," Ztsch. f. exp. Päd. 1913, 60.

- This diagram adapted from an already mentioned paper of mine ("Beziehungen zwischen d. Intelligenz u. dem Lernen u. Behalten," 43 ) was then used by me to illustrate differences in the reproductive ability of school ehildren. These differences, however, for reasons then given, I did not attempt to evaluate more precisely. 


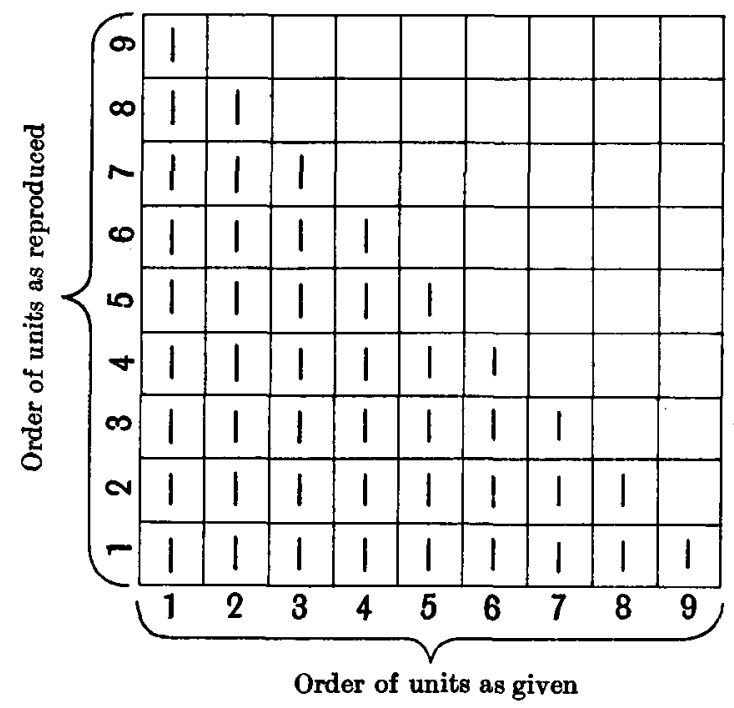

If now $r$ represent the number of units in the chief diagonal, $s$ the total number of units presented and $k$ any given reproduction of the rows, then

$$
k=\frac{r-m}{s-m},
$$

or, where $n$ is an uneven number,

$$
k_{1}=\frac{2 r-n+1}{2 s-n+1}
$$

and, where $n$ is an even number,

$$
k_{2}=\frac{2 r-n+2}{2 s-n+2},
$$

the values of $k$ lying between 1 and 0 .

This method, as the writer recognises, yields a very imperfect treatment of the results; it restricts the issue to too narrow a basis. It assumes, that while in the best case the rows are reproduced in the proper order, in the worst case they are reproduced in inverse order. In actual practice, the case assumed by Wagner as the worst is by no means actually the worst. Indeed, to reproduce a row of from six to nine units backwards is a feat requiring no small capacity. For a complete and regular backward reproduction of long rows, requiring as it does the breaking up of the forward associations of place and imagery, and the building up of new ones, calls for concentrated effort. 
greater than that required for the usual form of reproduction. This evaluation, too, like those mentioned before, fails to take into full account the differences of place value in the units of the row. To repeat the medial members of a long row is a much more difficult task than to repeat the last, or, in some cases, the first. Nor can such a method make allowance for fluctuations in the accuracy with which the rows are reproduced, this varying from row to row and depending upon the nature of the row, and the behaviour of the learner. In some rows, once the first unit has been learnt, the remaining units come quickly and easily to the tongue; in others the effort is greater and the units come up in isolated fashion, the subject often having but a vague idea of their place.

\section{The SPAN OF PREHENSION.}

Such then, in broad outline, are the methods hitherto adopted in the evaluation of the data obtained from experiments on immediate memory. As is evident, estimations of this nature are based almost entirely upon quantitative, rather than upon qualitative considerations. Moreover, in such cases, little attention has been paid to the analysis of the individual reproductions and to their varying differences. Table I, giving the number of times each row was correctly reproduced in the experiments described above, indicates this very clearly.

In the case of numbers, the threshold ${ }^{1}$ may be taken as varying for the adults between the sixth and the seventh unit rows, for the intelligent children between the fifth and the sixth unit rows, and for the less intelligent between the third and the fifth. For syllables, the threshold is, of course, lower, ranging for adults from the fourth to the fifth unit rows, for the intelligent children from the third to the fourth, and for the less intelligent from the second to the third unit rows. In the syllable rows, the differences are more marked owing to the greater difficulty experienced in reading and reproducing syllabic forms. To what extent however such differences are dependent upon the greater difficulty found in the synthesis of the syllabic units of the row, to the child's difficulty in reading, or to its power of adaptation, cannot be here decided. The figures show, too, that the boys give

1 The threshold is determined by the longest complete row of units which can be immediately and correctly repeated. 
328 Immediate Memory and its Evaluation
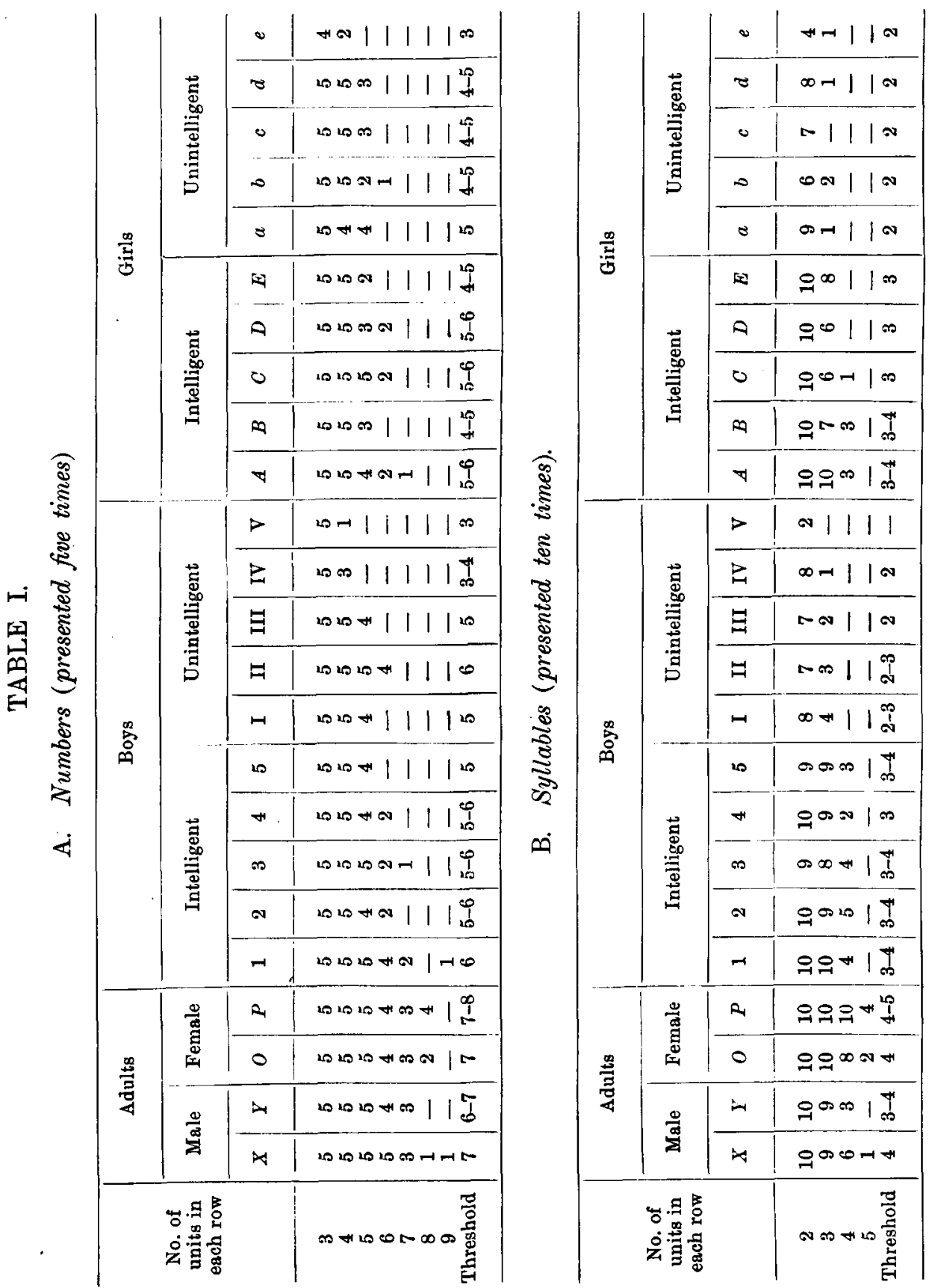
better results than the girls. It is also interesting to note that the best results of the boys are not so very much behind those of the adults; indeed, probably, the span of prehension in a boy of the age of ten is not much below that of the untrained adult.

This table, however, gives but a very general idea of the differences revealed in the process of learning, as observed in different individuals, for the attempt to apprehend the row as a whole often persists to a marked extent in long rows which are distinctly beyond the threshold. Evidence of this is seen in the results shown in Table II.

Sections A and B of Table II show the results of the presentation of a series of syllable and number rows to all the subjects. In the fourth of the number rows, there is some uncertainty in the replies of the adults. The numbers $1,3,6,7$ follow the order in which these numbers are generally used, hence the forward associations linking 3 , 6,7 are stronger than the association between $6,3,7$. In the case of the males, the order of the units in the sixth row shows more variation, the greater stress which has been placed upon certain of the units causing them to be reproduced first. In the seventh row this difference is still more marked and further some of the units here are forgotten. It is important, however, to notice that the row as a whole (die Gesamtvorstellung) is still remembered, though the constituent units may have lost their proper places. The repetition of the row maintains, too, in the main the freshness of the original impression. The same is to be noticed in the case of the boys and of the girls. Here again the fourth row has caused difficulties, not great enough, however, as far as the intelligent children are concerned, to destroy its unity. The fifth row, though some individual units are forgotten, exhibits similar features in the answers of $1,2,3,4$, and of $A$ and $B$. In the sixth, the difference in the replies has become more marked. Here the influence of the span has disappeared in all but the answers of 1 and 3 . One boy (1) has given the seventh row quite correctly, whereas the rest have only succeeded in reproducing scattered portions.

Owing to the more complex character of the units, the effort to reproduce the row as a whole is more clearly marked in the syllabic than in the number rows. The figures representing the threshold of immediate memory for syllable rows have been given above ${ }^{1}$. These figures, however, represent only the rows correctly repeated; they do not take into account those where the synthetic effort is still effectively 


\begin{tabular}{|c|c|c|c|c|c|c|}
\hline \multirow{10}{*}{$\frac{\infty}{\bar{\Sigma}}$} & \multirow{5}{*}{ 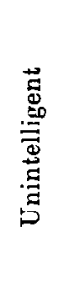 } & 2 & +++ & Conter & $\infty \infty+\infty 1$. & $\infty \sim-\infty \infty \infty$ \\
\hline & & $\tau$ & +++ & +++ & $+t+t$ & Has \\
\hline & & 0 & +++ & +++ & $\infty \infty \pi+1$ & $\infty x-1 \mid$ | \\
\hline & & $\infty$ & $++t$ & $+++t$ & $\infty \infty \infty \pi$ & ヘーホカの心 \\
\hline & & $\approx$ & ++ & +++ & $\infty$ ๓ & МलMU \\
\hline & \multirow{5}{*}{ 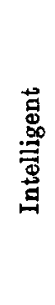 } & 由 & +++ & ++++ & 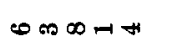 & $\widetilde{\sigma} \widetilde{0}=1$ \\
\hline & & $a$ & +++ & +++ & +++++ & +++++ \\
\hline & & 0 & +++ & +++ & ++++ & +++++ \\
\hline & & $\infty$ & $++t$ & $++t+$ & $\infty n \infty \infty$ & $N \pi \infty \overbrace{\pi 200}$ \\
\hline & & $\nabla$ & +++ & $++t+$ & $++++t$ & N N \\
\hline \multirow{10}{*}{$\hat{\rho}_{\dot{\infty}}^{n}$} & \multirow{5}{*}{ 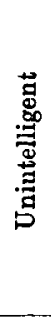 } & $>$ & $+t+$ & 0 ब & $\infty \infty \times 1$ & W LOCON I \\
\hline & & $E$ & +++ & +++ & $\infty \infty \mid$ | & $\infty+||||$ \\
\hline & & 刍 & +++ & ++++ & ++++ & $N+\infty \rightarrow \omega r$ \\
\hline & & $\Xi$ & +++ & ++++ & ++++ & N๑OH \\
\hline & & $\mapsto$ & $++t$ & $++t+$ & $++t+t$ & 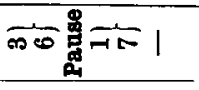 \\
\hline & \multirow{5}{*}{ 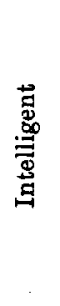 } & 10 & +++ & ++++ & ++++ & NHAncor \\
\hline & & 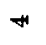 & +++ & ++++ & +++++ & +++++ \\
\hline & & $\infty$ & $++t$ & ++++ & $+t+t+$ & வ \\
\hline & & $\infty$ & $++t$ & $+++t$ & +++++ & +++++ \\
\hline & & - & +++ & ++++ & $+t+t+$ & ++++++ \\
\hline \multirow{4}{*}{ 苞 } & \multirow{2}{*}{ 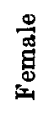 } & 2 & $++t$ & $++t+$ & $++t+$ & NオーM⿻上 \\
\hline & & 0 & +++ & ++++ & $+t+t$ & aH口x心 \\
\hline & \multirow{2}{*}{$\stackrel{0}{\frac{0}{\infty}}$} & $\rightarrow$ & $++t$ & +++ & $+t+t$ & +++++ \\
\hline & & 4 & +++ & $++t+$ & ++++ & +++++ \\
\hline \multirow{2}{*}{\multicolumn{3}{|c|}{ 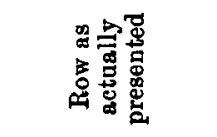 }} & $\infty \infty \infty$ & $0-10 x$ & $m \infty \infty \pi+$ & NHremt \\
\hline & & & $\mapsto$ & 曰 & 目 & B \\
\hline
\end{tabular}




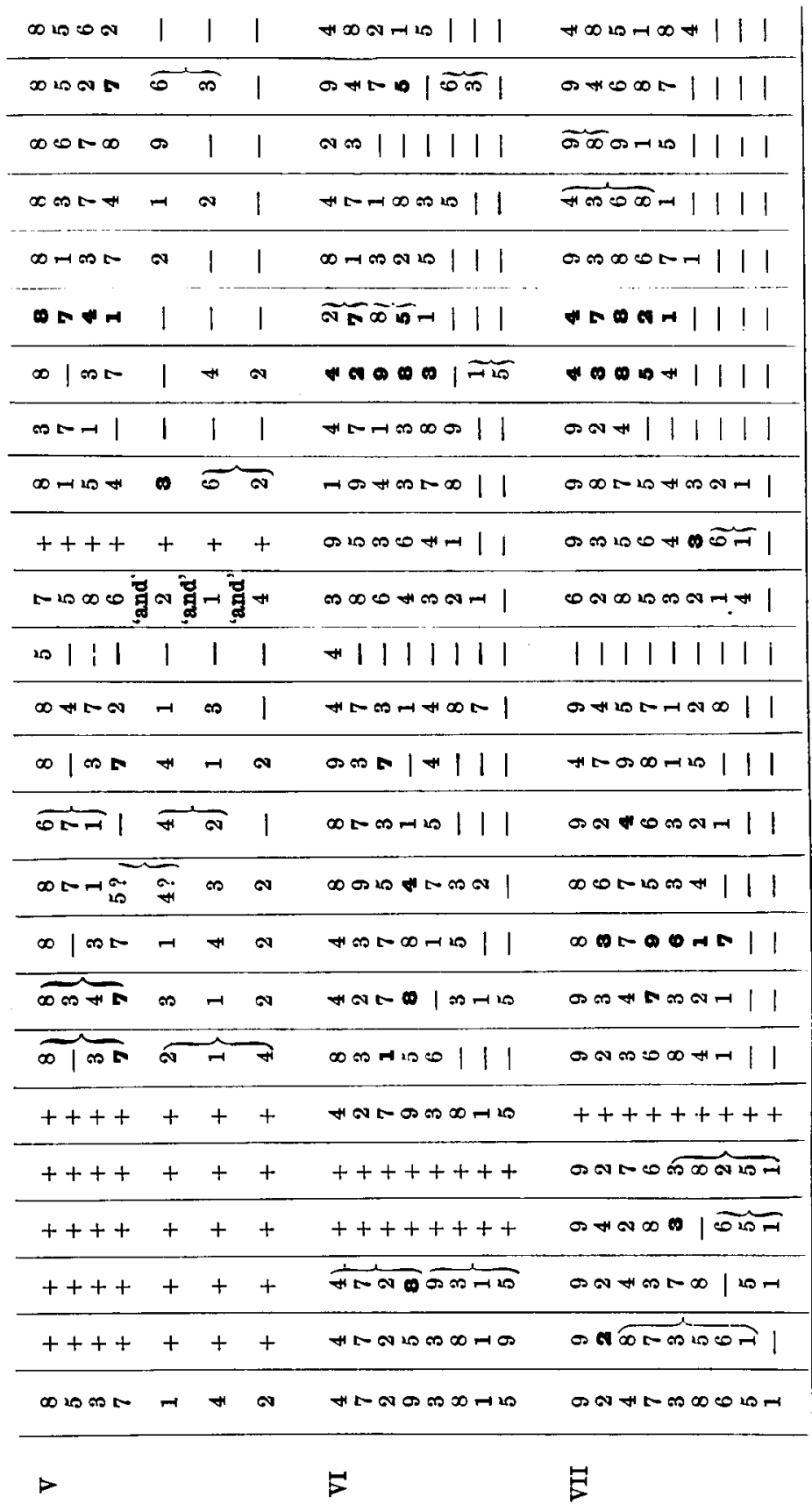




\section{Immediate Memory and its Evaluation}

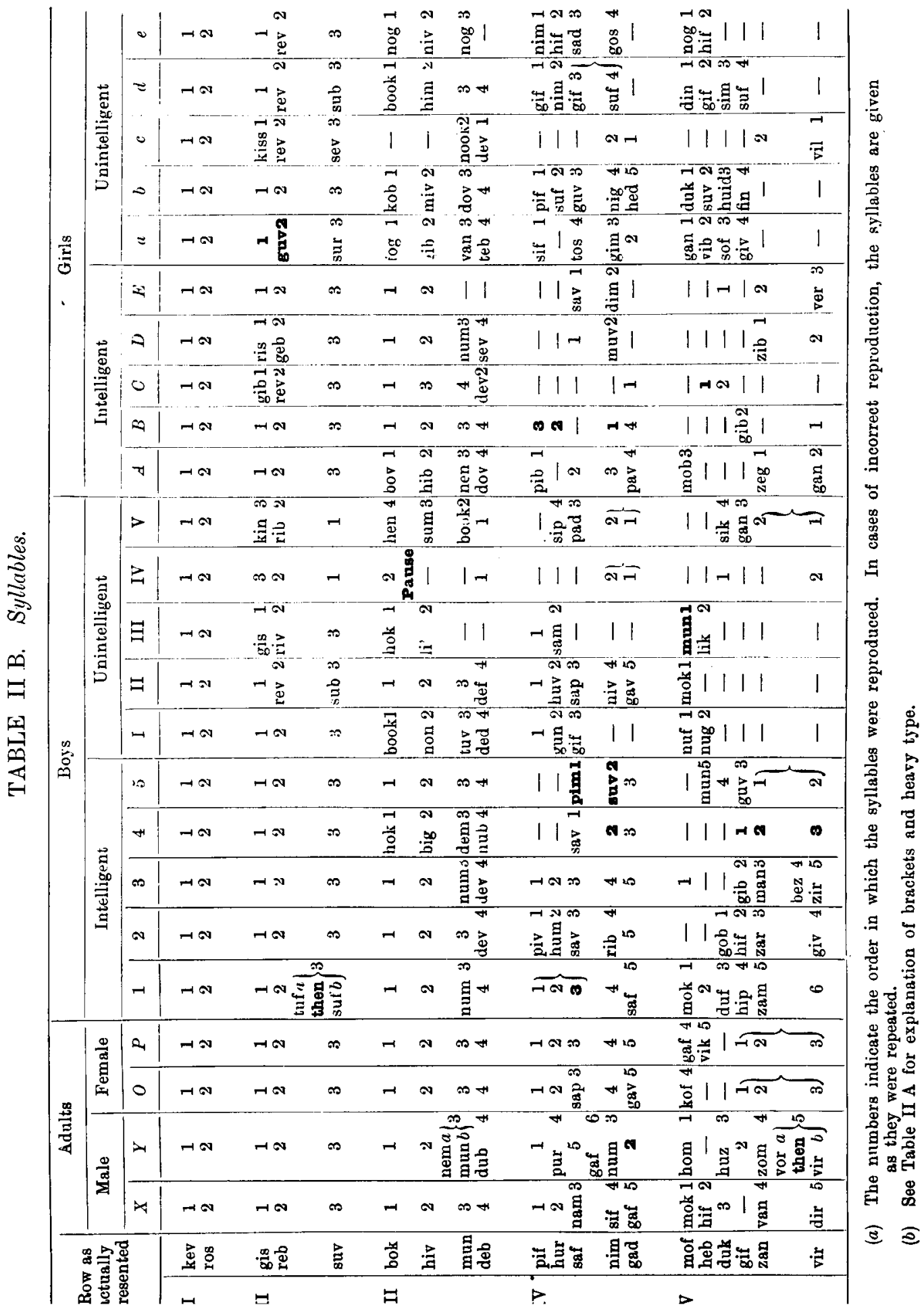


present. Each adult has, for instance, repeated, or reproduced the fourth row completely, but not in the proper order, whilst in the fifth row $X$ 's answer still bears marked traces of synthesis. A glance at the results obtained in the fourth and fifth rows by the intelligent boys and girls reveals the same characteristics.

These examples give evidence, then, that the span of prehension persists more or less actively in rows beyond the threshold, and moreover determines, in great part, the nature of the reproduction in such cases. A comparison of the difference of the threshold for numbers and for syllables strengthens the view that there is no very marked difference in the results obtained from intelligent and unintelligent children. What seems evident is that the apprehension of the row as a complex whole is determined largely by processes which vary with the degree of intelligence and with the mechanical or sensible nature of the material learnt.

Before, however, the varied effect of the span can be properly considered, a brief survey of the memory processes is necessary. Generally speaking, memory may be defined as the capacity to recall into the field of consciousness, after a given interval, impressions which have been once experienced, and to recognise these as old experiences. Thus, two processes have to be considered here, the learning of the material and its recall. The conditions attending the learning act allow of many variations. The material to be learnt can be presented in various ways and can be learnt in different forms, changing with the purpose which the learner has in view. Thus the material may be presented simultaneously or successively, it may be shown quickly or slowly, or again, it may be presented once or given sezeral times. Subjectively considered, the act of learning varies with the purpose of the learner ${ }^{1}$; for instance, to learn what has to be recalled after a short interval of time is quite a different matter from learning that which has to be retained for a long period. It is the recognition of this difference that has given rise to the distinction between immediate and mediate memory. Immediate memory, in the strict sense of the term, is the capacity to repeat impressions which have not entirely disappeared from consciousness, the expression following immediately upon the impression. This repetition, e.g., of a given row of syllables or numbers, depends in the first place upon the attention necessary

1 Cf. Meumann, "Beobachtungen über differenzierte Einstellung bei Gedächtnisversuchen," Ztsch. f. exp. Päd. 1912456. 
for the building up of effective and durable associations, and in the second, upon what has been termed the 'span of prehension' or the "mind's power of taking on certain material1". By this is meant the ability to receive and combine into a complete whole (die Gesamtvorstellung) a given number of isolated impressions, and to repeat these accurately, immediately after the material has been presented. We are, therefore, concerned here with processes distinct from those involved in the remembering and reproduction of material after a lengthy period of time. In the latter case, it is the learning and retaining for a lengthened period that is important, whereas, in the former, it is the immediate repetition of material presented once only ${ }^{2}$. Strictly speaking then, immediate memory is distinguished by the repetition of impressions which have not entirely faded from consciousness and which, therefore, bear in their repetition distinct traces of their original freshness. It is clear that this form of memory ${ }^{3}$ is found only in the repetition of those rows the length of which does not exceed the threshold, or, at any rate, exceeds it to a very small degree. Thus, when a subject repeats a row of six units correctly, but breaks down at a row of seven, the repetition of the six units is characteristically rapid, whilst there is often complete forgetfulness when a second attempt to repeat the units is made. In such rows, an effort is made to repeat the row as a whole, though on again exposing the row, the subject is frequently unaware that individual members of the row were originally present $t^{5}$. In rows just beyond the threshold, one of two things may happen. Either the attention is concentrated on the whole row, when usually the span breaks down entirely and but a few units are reproduced in haphazard manner (see Table II A, rows VI and VII for numbers and Table II B, rows IV and V for syllables), or the subject attempts, often unconsciously, a division of the row. In the former case it may often happen that if the first units of the row are again exposed, the whole

1 Jacobs, op. cit. 79.

2 Cf. Meumann, Ökonomie u. Technik des Gedëchtnisses, 41. Aal believes this can be more precisely formulated, see " Ein neues Gedächtnisgesetz," Ztsch. f. Paychol. Lxvr. 41.

- So far as the learning of rows is concerned.

4 As one child put it :- "You get them one minute, they go away the next."

5 Cf. Nagel, "Untersuchungen über Grundfragen d. Assoziationslehre," Arch. f. d. ges. Psychol. xxm1. 211-12. Nagel, in testing his subjects by the scoring method on the knowledge of syllables contained in rows learnt a few minutes previously, found that many syllables forming the rows just learnt were, in the scoring test, not only not reproduced, but not even recognized. Nevertheless, when asked to repeat the row in which these apparently unknown syllables occurred, the subjects gave them without difficulty. 
row, or most of it, is reproduced in regular sequence ${ }^{1}$. This fact would tend to strengthen the view that in immediate memory the attentive effort is directed to the synthesis of the elements into a combined whole in which each separate unit has almost entirely lost its individual character ${ }^{2}$.

When longer rows are presented, the results and the processes involved are of a somewhat different nature. The row is now too long to allow of synthesis into a unified whole, since the first, and often the medial, units have disappeared from consciousness before the last have been presented. Hence the reproduction of such long rows has two stages. First those units are repeated which still ring and persevere in consciousness as primary images; then comes the reproduction of units, sometimes in pairs, and sometimes singly, as chance associations may occur. These two stages are quite distinct, and are usually distinguished by the quickness with which the elements in the first 'trip,' as it were, off the tongue, whilst, in the second, there is a conscious seeking for association and an effort to recall. Evidence of this change as the rows grow longer may be seen in the results given in Table II.

Table III, which deals with a series of syllable rows, shows similar features.

Taking the adult replies first, it is seen that up to the third row the influence of the span is still present. In the fourth case with the exception of $X$ the synthetic effort has practically broken down, and the syllables are reproduced somewhat differently. In the replies of $Y$ and $O$ the syllables were reproduced slowly, usually with pauses between each, whilst in that of $P$ an attempt was made to reconstruct the row in backward order but with little success. The fifth row was still further forgotten and practically no synthesis is observable. $O$ and $P$ repeated two or three of the late syllables quickly. Then came a pause, with the reproduction, after intervals, of the other syllables. In these long rows, $P$ reproduced the first syllables by associating them with each other, or often with sensible words resembling them in sound, though this latter association was not a deliberate act during the presentation of the row. The same phenomena are to be noticed in the replies of the children. As the rows grow too long for their apprehension as a whole, so the results show the changed nature of the learning

1 See Table II B, row V. $X$ had reproduced this row as there given. He felt, however, that the first syllable inhibited the reproduction of the others. I therefore gave him mof, when he at once gave me "mof, heb, duk, van, dir."

2 See Nagel, loc. cit. 209-213, on the influence of the Gesamteindruck. 
336 Immediate Memory and its Evaluation

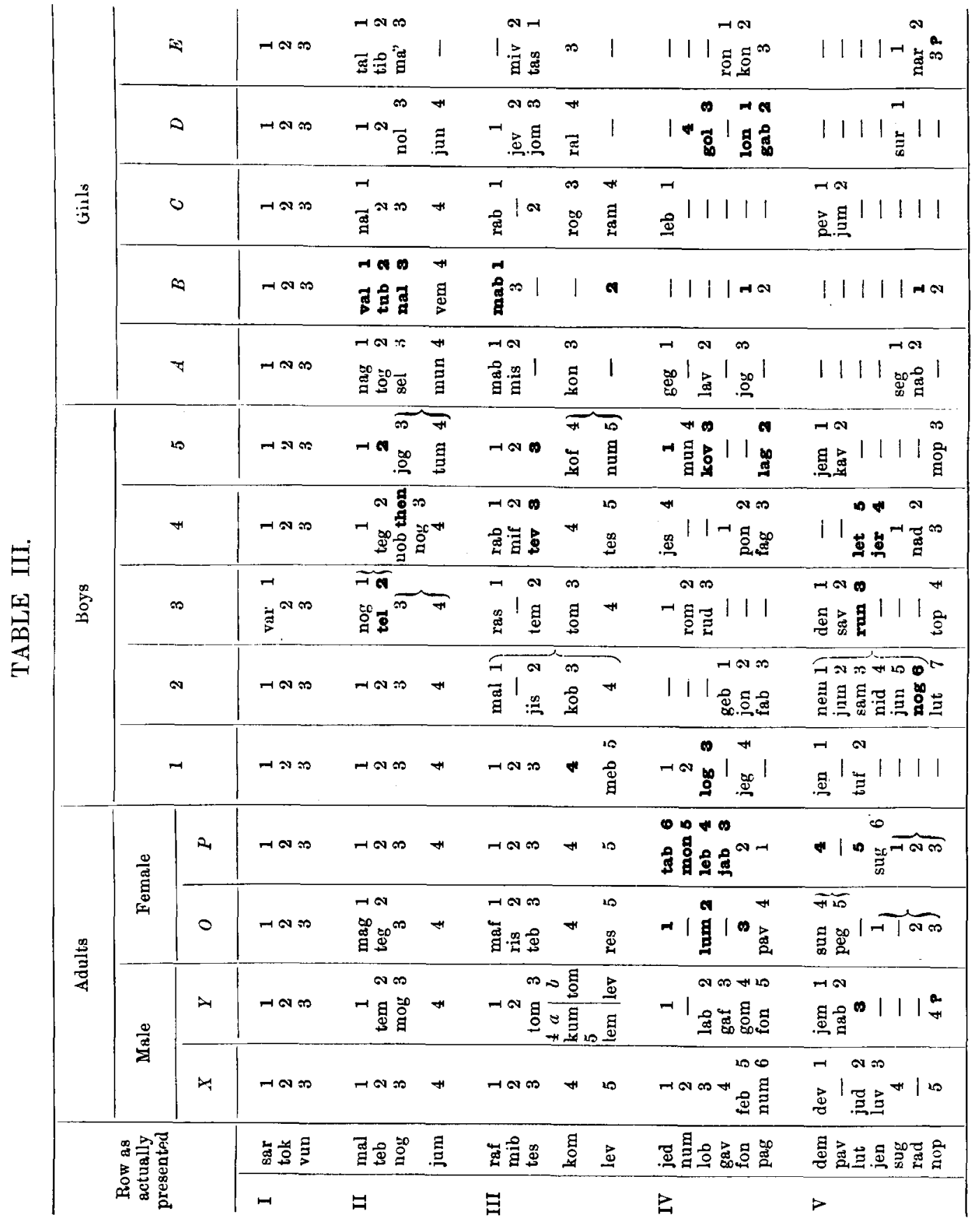


act. In the fourth and fifth rows the syllables are reproduced mainly as haphazard associations occur. If repetition takes place it is chiefly of the last two or three units, which are given quickly to make way for the more deliberative effort of reproduction. No attempt seems to be made, however, to repeat the whole or even grouped portions of the row, but merely to give isolated units as they are remembered.

Mere combined classifications of results, whether taken with regard to accuracy of form and of place, or of form alone, may thus often obscure factors which are of considerable importance ${ }^{1}$. Especially is this so with reference to evaluations based on the place value of the units. It frequently happens that in such long rows as V, VI, and VII of Tables II and III the last few units of the row are quickly and almost mechanically repeated, whereas the remainder are reproduced with considerable effort. These latter are recalled either singly or in association with others. If associated in pairs, and the row is not too long, they are correctly placed; if reproduced singly, only a vague idea of the place is present. A unit may thus be given as "near the end," "about the middle" and so on. In such cases, a vague awareness of the row as a whole remains. Often the first and last units are reproduced correctly, though not in their proper order. Nor, under these conditions, is it correct to conclude that the last units, because given first, are falsely placed, for though repeated first, their place in the row is generally perfectly well known when they are repeated. To reproduce them again in the hope of placing them properly, is to run the risk of building new associations of stress and of tone, which tend to weaken the original impressions. Especially is this the case with backward children. With them, the last elements of the row ring most strongly in consciousness, to the exclusion of most, if not all, of the other elements. Indeed, in material difficult of apprehension such as nonsense syllables, no synthesis is attempted; the child devotes its attention to the mere reading of the units. Hence the units remembered are reproduced singly, the last members of the row being given

${ }^{1}$ See the replies of $Y$ and $B$ to the IVth syllable row in Table II B. $Y$ gave the first and last syllables at once, then stopped and gave num, pur, adding that pur was second in the row. Then came saf and a little later gaf. In written answers the final result of this reply would probably read:- pif, pur, saf, num, gad, a result seemingly as good as those of $X, O, 1,2$, or $A$. Similarly $B$ reproduced the syllables singly with pauses between each reproduction. Answers of this nature are, however, of quite a different character from such replies as those of $X, O, 1,2$, and $A$. 
first, and in backward order. When questioned, however, the child is sometimes able to place them in their proper sequence.

A comparison of the replies of the intelligent and backward children will serve as illustration. Sometimes only one or two units from a row of five are reproduced by an intelligent child, whilst his more backward companion will give two and will often attempt to reproduce a third and fourth. The two cases, however, are examples of different forms of learning. The backward child does not apparently combine the units; his attention is more often directed to each individual unit and, in reproducing, he is thus able to give two or three correctly. On the other hand, the intelligent child may find a row of five units just long enough for correct repetition. He, therefore, attempts to combine the units into a complete whole and to repeat them as such. At times he may succeed, at others he breaks down entirely. In the longer rows, however, the first few units are held, as it were, in suspense whilst the last are being presented. As soon as the whole row is exposed, these last units are immediately repeated as a group, whilst the first units of the row are reproduced, as chance associations occur. In these rows, therefore, there is no longer one complete effort: Some units are repeated quickly, others reproduced more slowly, often by means of association with sensible words. The rows of syllables in Table IV may be taken as examples.

Here the third row reveals the influence of the span in each of the adult replies. The fourth on the other hand shows different characteristics. In the cases of $X, Y$ and $P$ efforts were made at a repetition of the whole row with but doubtful success. $O$ found the third row just a little too difficult for her and so, in the fourth, endeavoured to give as many syllables as possible. The first to the fourth units were repeated quickly, as a group; then, after a pause, came the fifth and sixth, fob being probably remembered through association with fob (a watch pocket), and thus reviving the association with kir, the unit next following. In the fifth row, the span has practically disappeared. $X$ reproduced the syllables in pairs, with a pause between each, in complete contradistinction to the rapid form of the repetition which he adopted in the shorter rows. $Y$ adopted the same procedure, jan, a syllable which he had incorrectly reproduced in the fourth row, being here correctly given instead of $\mathrm{raz}$, a syllable of like sound, occupying the same position in the row. The case of $P$ is of interest. Her threshold fluctuated between rows of four and five units, the failures in rows of five syllables being mainly due to transposition of the consonants. 


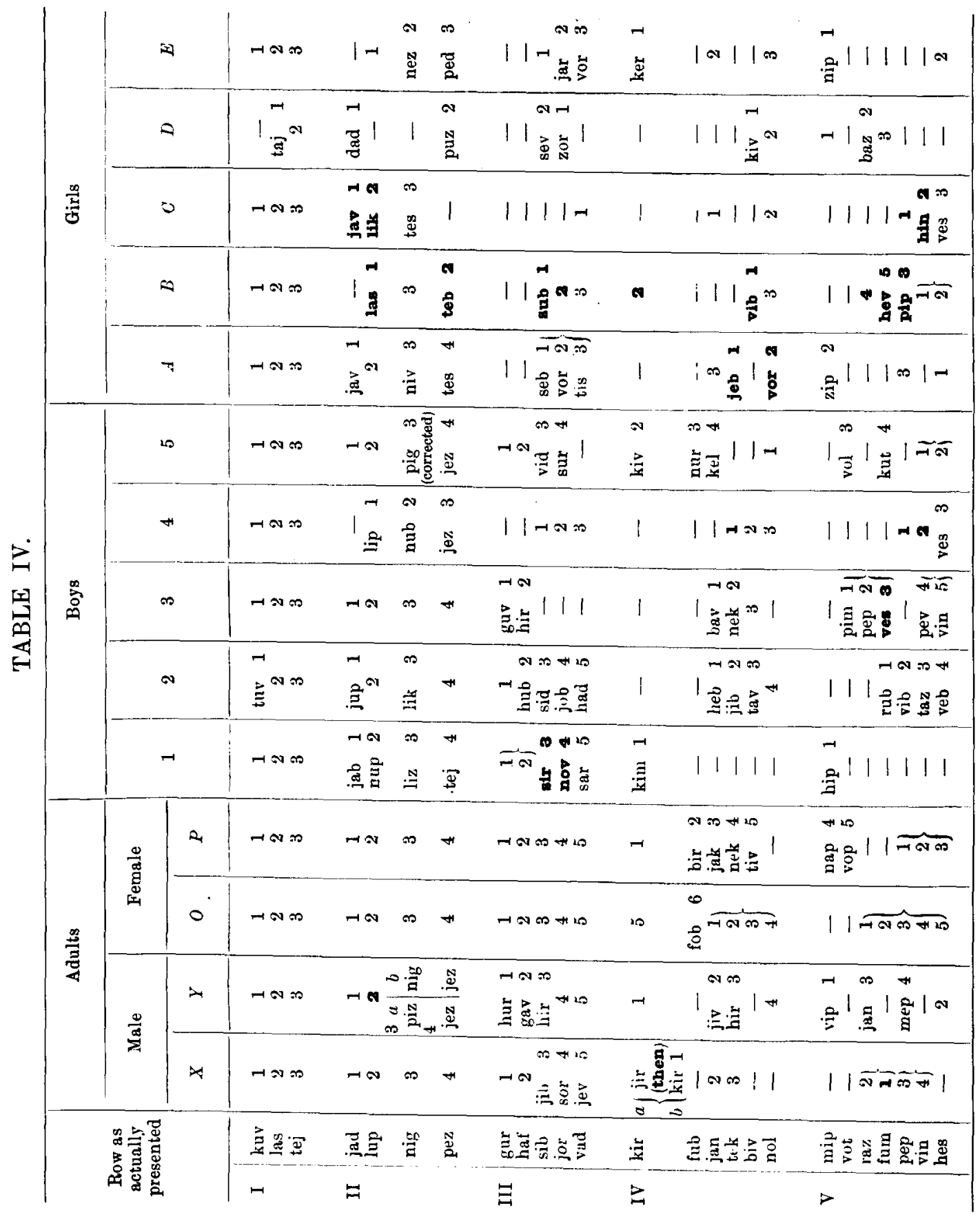


The unity of the row was, however, preserved in each case. In the rows of four units, the procedure varied. Sometimes an attempt was made to repeat the row as a whole, with results similar to those given here. At other times, reproduction took place on the lines shown in the fifth row, i.e., the last few syllables were repeated quickly, and then effort was made to reproduce the rest of the row.

The same is to be noticed, though not to such a marked extent, in the replies of the intelligent children. The answers to the second and third rows vary considerably as the synthetic effort succeeds or fails. In the fourth and fifth rows there is some improvement, owing to the different aim kept in view, for in these rows the children seem to aim at reproducing as many syllables as possible. With no introspection to guide us, however, it would be dangerous to base any comparison on such purely objective results.

\section{Errors of partial Reproduction.}

Further effects of the differences in reproduction noticed above are to be observed in an examination of the numbers and syllables incorrectly reproduced. In the short rows, where the primary sensory elements are still 'ringing' in consciousness, characteristic interchanges of consonants and vowels take place. It is rare, however, that false syllables or sensible words are inserted. The row is a short complete unit in consciousness, and any change in its original constitution follows along lines which vary according to the nature of the units and of the individual. The first evidence of the weakening of the original impressions is in an interchange of the units of the row and, in the case of syllables and words, the interchange of consonants and vowels. The following reproductions are examples of this :-

\section{A. Numbers.}

\begin{tabular}{c|c|c|c|c}
\hline $\begin{array}{c}\text { Row as } \\
\text { given }\end{array}$ & \multicolumn{4}{|c}{ Row as reproduced } \\
\hline & & & & \\
\hline 5 & 5 & 5 & 5 & 5 \\
7 & 9 & 2 & 2 & 7 \\
2 & 2 & 7 & 7 & 9 \\
9 & 7 & 9 & 9 & 2 \\
6 & 6 & 6 & 6 & 6 \\
\hline
\end{tabular}


B. Syllables.

\begin{tabular}{|c|c|c|c|c|c|c|c|c|c|}
\hline \multirow{2}{*}{$\begin{array}{c}\text { Row } \\
\text { as } \\
\text { given }\end{array}$} & \multicolumn{4}{|c|}{ Adults } & \multicolumn{5}{|c|}{ Boys } \\
\hline & $X$ & $\boldsymbol{Y}$ & $o$ & $P$ & 1 & 2 & 3 & 4 & 5 \\
\hline $\begin{array}{l}\text { vig } \\
\text { nup } \\
\text { tem }\end{array}$ & $\begin{array}{l}1 \\
2 \\
3\end{array}$ & $\begin{array}{c}1 \\
\text { nuf } 2 \\
\text { teb } 3\end{array}$ & $\begin{array}{c}\text { zig } 1 \\
2 \\
3\end{array}$ & $\begin{array}{r}1 \\
2 \\
3 \\
\end{array}$ & $\begin{array}{l}1 \\
2 \\
3\end{array}$ & $\begin{array}{l}\text { vin } 1 \\
\text { nub } 2 \\
\text { sen } 3\end{array}$ & $\begin{array}{c}1 \\
\text { nep } 2 \\
\text { tum } 3\end{array}$ & $\begin{array}{l}\text { nig } 1 \\
\text { vup } 2 \\
\frac{3}{3}\end{array}$ & $\begin{array}{c}1 \\
\stackrel{2}{2} \\
\text { ten } 3\end{array}$ \\
\hline sif & 4 & $\operatorname{sig} 4$ & 4 & $\begin{array}{c}\text { siv } \\
\text { or } \\
\text { siff }\end{array}$ & 4 & fis 4 & 4 & 4 & 4 \\
\hline
\end{tabular}

The incorrect sequence characteristic of numeral rows, and the transposition of consonants or vowels in syllables and words otherwise correctly given, is probably the first stage of forgetting. It takes place, generally, in rows near the threshold where the conception of the units of the row, combined to form a complex whole, is still present in consciousness, but where however the individual members are becoming less firmly fixed. In slightly longer rows appears the further stage, when the units are misplaced or sometimes entirely forgotten. In such cases, the unity of the row is broken, though the conception of the whole row as a scheme (die Gesamtvorstellung) still persists. It is as if one were able to pronounce a word but not to spell it. The following tables illustrate this:-

A. Numbers.

\begin{tabular}{c|c|c|c|c}
\hline $\begin{array}{c}\text { Row as } \\
\text { given }\end{array}$ & \multicolumn{5}{|c}{ Reproductions } \\
\hline & \multicolumn{5}{|c}{} \\
\cline { 2 - 4 } 9 & $\frac{5}{8}$ & 9 & $\mathbf{3}$ & - \\
3 & $\frac{3}{8}$ & $\frac{5}{5}$ \\
5 & 9 & $\frac{8}{8}$ & 8 \\
8 & 1 & 1 & 1 & 1 \\
1 & 6 & 6 & 6 & 9 \\
\hline
\end{tabular}

B. Syllables.

\begin{tabular}{|c|c|c|c|c|c|c|c|c|c|}
\hline \multirow{2}{*}{$\begin{array}{l}\text { Row } \\
\text { as } \\
\text { given }\end{array}$} & \multicolumn{4}{|c|}{ Adults } & \multicolumn{5}{|c|}{ Boys } \\
\hline & $x$ & $\boldsymbol{Y}$ & $o$ & $P$ & 1 & 2 & 3 & 4 & 5 \\
\hline $\begin{array}{l}\text { vem } \\
\text { rud } \\
\text { sep } \\
\text { faz } \\
\text { mig }\end{array}$ & $\begin{array}{c}1 \\
\text { nub } 2 \\
3 \\
\text { \} viz } 4\end{array}$ & $\begin{array}{c}\text { vom } 1 \\
= \\
=\end{array}$ & $\begin{array}{c}\text { rem } 1 \\
\text { rub } 2 \\
\text { sek } 3 \\
\text { fab 4 } \\
\text { riz } 5\end{array}$ & $\begin{array}{c}1 \\
\operatorname{rub} 2 \\
\text { sef } 3 \\
\overline{4}\end{array}$ & $\begin{array}{c}1 \\
\text { rup } 2 \\
\text { sem } 3 \\
\operatorname{ras} 4 \\
\text { vig } 5\end{array}$ & $\begin{array}{c}\text { rem } 1 \\
\text { nud } 2 \\
3 \\
\text { man } 4 \\
\operatorname{giv} 5\end{array}$ & $\begin{array}{c}1 \\
\text { faz } 2 \\
\text { sup } 3 \\
\text { vem } 4 \\
5\end{array}$ & $\begin{array}{c}\text { vab } 1 \\
\operatorname{rup} 4\} \\
\operatorname{mez} 3\} \\
- \\
\text { bs } 2\end{array}$ & $\begin{array}{l}\mathbf{1} \\
2 \\
\\
-\end{array}$ \\
\hline
\end{tabular}


The numbers need no comment. In the syllable rows $X$ was disturbed by the sibilants and gave viz a combination of faz and mig as the last syllable. $Y$ was not sure of the first syllable, stopped to consider it, hesitated and lost the row. $O$ gave the complete row, with its units, however, much weakened. $P$ forgot the fourth unit, the transition from the $p$ in sep to the $f$ in faz tending to a confusion of the two syllables. The replies of the boys were similar. 1, 2 and 3 gave the whole row in varying degrees of accuracy. 3 forgot the second syllable and combined it with the third to give sup, faz being transferred from the fourth to the second position, in consequence, probably, of the tendency to accentuate the penultimate syllable in rows just too long for accurate repetition ${ }^{1}$. In the cases of 4 and 5 the reproduction of the row is not so correct. 4 gave the first and last syllables with pauses between each, while rup and mez, combinations of the second and third, and of the fourth and fifth respectively, were (after a pause) given together.

In the longer rows, the nature of the errors becomes naturally more complex. In the case of syllables, associations with sensible words often lead to confusion. Moreover, associations with other syllables having similar consonants or vowel sounds continually occur. This, too, is the cause of the incorrect reproduction of words and syllables of similar sounds occupying similar places in rows previously exposed ${ }^{2}$.

The frequency of the mistakes in reproduction has given rise to characteristic differences in the work of intelligent and backward children. One of these is the perseveration of distinct types of combinations. The mechanical act of learning is dependent, as Müller ${ }^{3}$ points out, on two factors. These are, first, association, and, secondly, the physiological tendency of impressions to persevere for some time with somewhat of their original freshness. In everyday life this phenomenon plays a useful rôle. When, however, it gets the upper hand, the act of learning suffers considerably. The undue perseveration of mental images has often been noted as a sign of backwardness. In the learning of rows of numbers, syllables, or sensible material it may be noted in two forms ${ }^{4}$. In the first, one unit or combination of units may

1 See p. 347. $\quad$ See the reply of $Y$ to Row V in Table IV.

3 Müller u. Pilzecker, Exper. Beiträge zur Lehre vom Gedächtnis, 75.

" Cf. Rusk, "Mental Association in School Children," This Journal, 1910. Rusk distinguishes between Perseveration and Persistence- "the repeated re-instatement in consciousness of the same image." This "perseverance of content in imagery," he terms persistence to distinguish it from "the mere perseverance of form." Cf. Jesinghaus, "Zur psychologischen Theorie des Gedächtnisses," Psychol. Stud. vir. 365 ff. 
dominate the repetition of a row to the disadvantage of the others; in the second, certain combinations appear row after row in almost regular sequence. It is probable that the constant persistence of one image and its reproduction is due, in great part, to lack of ability to concentrate upon the other units of the row. The persisting image is constantly forced into the foreground, and the child is neither able to repress it, nor to concentrate upon the reproduction of the remaining units. Intelligent children attempt to give a complete reproduction of the row, or, if this is impossible, to reproduce associated units. With backward children, the persistence of the same image breaks up the associations and so spoils the reproduction of the row.

The first of the above-mentioned modes of perseveration, that in which certain elements tend to dominate reproduction within the row, is not to be confounded with the mere interchange of vowels or consonants. In the former case, a consonant or vowel, or even a whole syllable, may interfere with the reproduction of the row. Especially is this so when a syllable or word happens to present any special difficulty in reading. Thus, for the row het, gos, lun, vap was given hes, gos, lun, ves, the combination of het and gos having been more strongly impressed to the disadvantage of het and vap. Similarly, the row per, $h i k$, vud, kes, nem was reproduced as ruk, tus, nus, vut, tiv; whilst the row mof, heb, duk, gif, zan, vir gave din, gif, sim, suf 1 . In number rows, numbers following the numerical sequence are often inserted (e.g., see Table II A), whilst often even numbers are followed by even and odd by odd.

The tendency of certain elements to dominate reproduction is, perhaps, not so characteristic a form as that of iteration ${ }^{2}$. This, too, is a mode of perseveration found most frequently in the reproductions of backward children ${ }^{3}$. It occurs, not only in senseless syllables, but also in sensible words, in the latter case showing, as Burt points out ${ }^{4}$, that sensible words are often not associated with any meanings, but are reproduced as primary sensory images. When numbers are exposed, a combination of two or three digits, once associated, is reproduced time after time. In many cases, the reproduction takes the form of mere repetition of the digits in numerical sequence. Thus the row

1 See Table II B.

2 Wreschner, "Die Reproduktion u. Aseoziation von Vorstellungen," Ztsch. f. Psychol. Ergänz.-Bd. III. 237 f. Chap. on Perseverationstendenzen.

${ }^{8}$ Meumann, "Intelligenzprüfungen an Kindern d. Volksohule," Ztsch. f. exp. Päd. I. 67, 96.

Loc. cit. 144. 
829465 gave 89 (pause) 645 . The succeeding rows of the same series were then reproduced as follows:-893745;893472;89362; 897325 , the figures 893 appearing in each reproduction. In another series 8137 was given in almost regular sequence. Combinations of this nature do not appear to persevere in more than one series, but seem to be built up anew in the initial short rows of each series and then to be forgotten as soon as the series is ended. These short rows are often repeated correctly, though their dominant units, or the combinations composed of them, will often persist and disturb the reproduction of the longer rows of the same series.

Syllabic rows show this persistence in still more exaggerated form. Indeed, the strangeness of the material and the resulting difficulty in reading may account for the fact that a form once rendered familiar is not only reproduced, but even read time after time. In many cases, sensible words similar in sound to a unit of the given row are substituted for this unit, and then tend to persevere. The following answers to a series of seven syllabic rows (see Table IV), consisting respectively of from two to eight syllables, will serve as examples:-

\begin{tabular}{|c|c|c|c|c|c|c|c|}
\hline Rows of & 2 & 3 & 4 & 5 & 6 & 7 & 8 \\
\hline & $\begin{array}{c}\text { vas } \\
\text { ged } \\
-\end{array}$ & $\begin{array}{l}\text { lass } \\
\text { gev } \\
\text { jess }\end{array}$ & $\begin{array}{c}\text { lak } \\
\text { giv } \\
\text { ged }\end{array}$ & $\begin{array}{l}\text { gab } \\
\text { giv } \\
\text { tos } \\
\text { giv }\end{array}$ & $\begin{array}{l}\text { kav } \\
\text { giv } \\
\text { tos } \\
-\end{array}$ & $\begin{array}{l}\text { van } \\
\text { gav } \\
\text { gos } \\
\text { vip }\end{array}$ & $\begin{array}{l}\text { kal } \\
\text { giv } \\
\text { gas }\end{array}$ \\
\hline
\end{tabular}

The first row of two units (vas, ged) was read correctly. They have, however, almost completely dominated the reproduction of the following rows of the series. Often, as is the case with tos in the above example, units appear at intervals and are then forgotten.

Another factor influencing correct reproduction is that known as regressive, retroactive, or backward inhibition ${ }^{1}$. The units composing rows successively presented do not disappear simultaneously from consciousness, but fade away in more or less regular sequence. The recall of any member of a given row is therefore dependent, in a large degree, upon its place in the row, the nearer the end of the row the fresher is its primary imagery. Thus, the last units presented exercise an inhibitory influence on their more remote fellows, so as often to

1 Cf. Müller u. Pilzecker, op. cit. 144-178. They distinguish between effectual generative and retroactive inhibition. 
cause them to fade away entirely, the inhibition becoming more effective the further removed the units are from the end of the row. One reason for this is that the persistence of the primary imagery of the units exposed last weakens those previously presented, so that the latter are often forgotten. This occurs chiefly in the longer rows, though it is often met with, in the case of backward children, in the shorter ones. The child being unable to overcome the distraction caused by the persisting images of the units last exposed ${ }^{1}$, these are repeated more or less correctly and the first units are then given after frequent pauses. It may, therefore, often happen that the backward repetition of a row is a device resorted to in order to obtain some measure of success. Those units exposed last have first to be rapidly repeated, before attention can be concentrated on the rest of the row.

Regressive inhibition is not an essential sign of backwardness; intelligent children often have recourse to backward reproduction as the best and easiest, if not the only method. When, however, it is found persisting in row after row it may be taken as symptomatic of low intelligence. The inhibition may manifest itself in various forms, according to the rate at which the row is forgotten. The whole row, for example, may be repeated in inverse order, portions of it may be combined and reproduced as a group, or, where the row is long, isolated units may appear in haphazard order. The backward reproduction of a whole row is not of frequent occurrence, though often unintelligent children reproduce even rows of two units backwards. The following are the reproductions of four children ( 4 an intelligent boy and $B$ an intelligent girl; $\mathrm{V}$ a backward boy and $c$ a backward girl) when given rows of from two to five syllables:-

I.

\begin{tabular}{c|c|c||c|c}
\hline Row as given & 4 & $B$ & $\mathrm{~V}$ & $c$ \\
\hline taj & 1 & 1 & 2 & 1 \\
kos & 2 & 2 & 1 & 2 \\
\hline
\end{tabular}

\begin{tabular}{l|c|c||c|c}
\hline \multicolumn{3}{|c|}{ II. } \\
\hline Row as given & 4 & $B$ & V & $c$ \\
\hline $\begin{array}{c}\text { gub } \\
\text { tef } \\
\text { sur }\end{array}$ & 1 & 1 & 3 & $\begin{array}{l}\text { gef 1 } \\
\text { tuv 2 } \\
\text { sef 3 }\end{array}$ \\
\hline
\end{tabular}

1 Cf. Galton, "Notes on Prehension in Idiots," Mind, 1887, 82. 
III.

\begin{tabular}{|c|c|c|c|c|}
\hline Row as given & 4 & $B$ & V & $c$ \\
\hline $\begin{array}{l}\text { ser } \\
\text { kav } \\
\text { luf } \\
\text { tig }\end{array}$ & $\begin{array}{c}\text { kur } 1 \\
\text { sav } 2 \\
3 \\
4\end{array}$ & $\begin{array}{l}1 \\
2 \\
3 \\
4\end{array}$ & $\begin{array}{c}\operatorname{tav} 4 \\
\operatorname{vuz} 3 \\
\operatorname{luv} 2 \\
1\end{array}$ & $\overline{\text { lef } 2}$ \\
\hline
\end{tabular}

IV.

\begin{tabular}{|c|c|c|c|c|}
\hline Row as given & 4 & $B$ & $\mathrm{~V}$ & $c$ \\
\hline $\begin{array}{l}\text { per } \\
\text { hik } \\
\text { vud } \\
\text { keg } \\
\text { nem }\end{array}$ & $\left\{\begin{array}{r}\text { ker } 4 \\
1 \\
2 \\
3\end{array}\right\}$ & $\frac{\text { ver } 1}{\frac{2}{2}}$ & $\begin{array}{c}\bar{Z} \\
\underset{\mathbf{p i m}}{3} \\
\mathbf{2} \\
1\end{array}$ & $\frac{-}{\underset{2}{2}}$ \\
\hline
\end{tabular}

Up to the third row, the faults of 4 and $B$, the intelligent children, are not serious. 4 , in the third row, however, has transposed the initial consonants in the first two syllables. Both results show that a complete repetition of each of the rows I to III has been attempted. In the fourth row, 4 repeated the last three syllables in their proper order, then paused in an endeavour to get the first two, and finally gave a combination of them in ker. In the case of $B$, the failure to reproduce is more marked. Every syllable was reproduced slowly, with distinct pauses between each reproduction, and it is clear that but a vague conception of the whole row was present. Quite different is the nature of the reproductions of $\mathrm{V}$ and $c$, the two backward children. $\mathrm{V}$ gave the first two rows backwards; asked to repeat the second in proper order, he failed completely. In the third and fourth rows, the last two syllables were given slowly and in inverse order; then after a pause came vague guesses at the other syllables. The case of the girl $c$ is similar. After the second row, consisting of three syllables, this child invariably gave the last two syllables of the row, sometimes correctly, often not, and always in their inverse order. 


\section{IMPRESSION AND EXPRESSION ${ }^{1}$.}

Finally, the manner in which the material is learnt and reproduced by intelligent and by backward children gives typical differences. When an intelligent child is faced with a row, the units of which are successively presented, it reads each unit deliberately and clearly, with no marked emphasis until the end of the row is reached. The last unit is, however, read with a distinct accent, implying that the end of the row has been reached, and that, moreover, each unit has been read, not as an isolated element, but as a connected member of a definite whole. In rows near the threshold, this method of reading may often give unfavourable results. The child tends to be uncertain of the length of the row and, having lost count, is not sure which is the last unit. In such cases, the end accent often falls, not on the final unit but on the penultimate (the last being read alone and often with a note of unexpectedness). When such is the case, the reproduction suffers. The last two units, strengthened by this involuntary place accentuation, are immediately repeated, but the unity of the row is broken and only scattered units of the remainder are reproduced. This factor probably accounts for that state of confused forgetfulness observed in the attempt to repeat rows just too long for correct repetition. When such rows are repeated correctly, they are given rapidly, often more rapidly than they were presented. As one subject put it, "the numbers come naturally," the same posture, tone and accent being adopted in both cases.

Backward children, on the other hand, rarely seem to attempt any synthesis of the rows. The latter are read in an even and monotonous tone, the units being frequently shouted aloud, with a heavy pause between each. Further, every single act of impression seems to constitute a single isolated event. When the units are exposed by means of an apparatus ${ }^{2}$, the backward child is often found reading the syllable, or word, as the next is about to be exposed. The reproduction follows in the same isolated and mechanical manner, a pause occurring between each unit, in complete distinction from the rapid repetition of the intelligent children. The pause between the impression of the row and its

1 See my "Beziehungen zwischen d. Intelligenz, etc.," 6]-2.

2 It is not without interest to note that the exposure of the rows by means of the cardboard sheet seems to present difficulty to those who learn mainly by means of visual imagery. The moving of the sheet breaks up the continuity of the imagery and thus of the row. 
reproduction is also longer in the case of backward children. They seem to find the transition from the act of impression to that of reproduction a task of some difficulty. It is this facile adjustment to the varying aim in learning which seems often to play a large part in the determination of the results ${ }^{1}$.

\section{Conclusions.}

I. Inferences previously drawn from experiments on immediate memory take no account of individual differences in the processes of repetition and of reproduction, of repetition in rows near the threshold and of both repetition and reproduction in those rows too long to permit of apprehension as a single whole.

II. In the learning of rows near the threshold, intelligent children apprehend the row as a complex whole, each unit being linked with the others and regarded as forming part of the whole. Backward children tend to learn each unit as isolated and almost as self-complete.

III. Perseveration in the reproduction of the rows may take place in two forms:-

(a) in the undue perseveration of a dominant number or consonant or vowel sound in the reproduction of a single row, or,

(b) in the appearance of combinations of units, or of single units, previously given and perseverating throughout a series of rows.

IV. The present experiments confirm previous work in showing that the influence of perseveration and of regressive inhibition, whilst not in themselves indicative of backwardness, are, however, more marked in the case of backward than of intelligent children.

1 See Burt, op. cit. 168.

(Manuscript received 26 July, 1914.) 